\title{
Reform Practice of Evaluation Method of Drawing Courses in Chinese Colleges Adapting to Advanced Manufacturing Technology
}

\author{
Yonggang Dong \\ College of Mechanical Engineering \\ Yanshan University \\ Qinhuangdao, China 066004 \\ d_peter@163.com
}

\author{
Jianfeng Song \\ College of Mechanical Engineering \\ Yanshan University \\ Qinhuangdao, China 066004 \\ songjianfeng@ysu.edu.cn
}

\begin{abstract}
The greater demands have been placed on the Chinese higher education system in recent years with the development of Advanced Manufacturing Technology. Characteristics of drawing courses in Chinese colleges were introduced firstly and the demand of Advanced Manufacturing Technology for the reform of engineering education was presented. Moreover, the shortcomings of traditional assessment system and teaching model of drawing courses were listed. Furthermore, the reform practice of drawing courses was carried out in Yanshan University, and the plans and rules for the implementation of assessment method were listed. In the end, the single achieving degree of ability of every student and mean achieving degree of ability of one class were given and discussed, and the existing problem during the reform practice were found and measures for improving the performance of drawing class were listed.
\end{abstract}

Keywords-Drawing courses; OBE; Degree of achieving the ability; Continuous improvement

\section{INTRODUCTION}

Development and application of AMT(Advanced Manufacturing Technology) depends on the ability of human beings, such as studying ability, abstracting ability and creativity etc. Therefore, it is the ultimate aim for Chinese higher education system to cultivate some people who have the abilities of innovation, creation and active learning ability by themselves.

Face to the challenge of Advanced Manufacturing Technology, Chinese engineering education system have had to be reformed in following three aspects, education concept, education thoughts and education mode. The traditional education concept is focus on teaching theoretical knowledge to the student, and the student is just a passive role to accept the abstract knowledgeable and most of students don't know how to solve the engineering problems by the theoretical knowledge. So it is difficult for the most of graduated students to meet the requirements of their work unit for lacking engineering application skills ${ }^{[1,2]}$.

Therefore, it is necessary and indispensable to strengthen the engineering practice and engineering application training during the teaching process by setting up practice unit in the lesson.

In addition, during the process of teaching and studying, the "spoon - feeding" type of teaching should be given up, and the curiosity and activity of students should be inspired to study and think actively by themselves by reasonable arrangements of teaching contents and practice training. Undoubtedly, this is an effective way to improve the creativity and innovation ability of students ${ }^{[3]}$.

\section{Characteristic OF DRAWING COURSES IN CHINESE COLLEGES AND ITS TEACHING MODE}

\section{A. Characteristics of drawing courses in Chinese colleges}

The drawing class is a foundation course for corresponding major or subject, and it is an important technical foundation course for students studying in colleges of science and engineering, especially for the students whose major is mechanical engineering or similar major. This courses aims at cultivating the drawing ability and the ability of reading the engineering drawings. Therefore, the drawing courses are compulsory in Chinese colleges of science and engineering, and the class hour is between 60 hours and 90 hours and its credit is between 3.5 and 5.5.

\section{B. Teaching mode of drawing courses}

Teaching mode of drawing courses include classroom teaching, homework practice, exercises tutorials and drawing practice. General speaking, the number of students is not greater than 60 and this course will be taught two times a week.

\section{Examination method of drawing courses}

This courses will be examined by the way of closed book, and the contents of the test include adding the third view according to the two given views of complex forms, standard parts and common parts, reading the part drawing, apart and drawing some parts from an assembly drawing of equipment. The number of examination questions is generally 7 , and the full marks of these courses are from the test paper without any regular grades or performance points.

\footnotetext{
${ }^{1}$ Sponsored by Teaching Reform Project of Yanshan University(JG2016ZX03)
} 


\section{REFORM PRACTICE OF TEACHING MODE ON THE DRAWING COURSES OF CHINESE COLLEGES}

\section{A. Problems existed in the transitional teaching mode of drawing courses in Chinese colleges}

In traditional teaching mode, the process of teaching and studying always revolve around the teaching program, and the teaching contents are restricted by the teaching program and corresponding knowledge points. During the whole activity of teaching and studying, the participation degree of students and the flexibility of teaching schedule are all low. After the courses have been finished, some students don't know how to choose suitable drawing methods to express the complex engineering parts reasonably and flexibly. Moreover, some students don't recognize the importance of national standard of China and corresponding industry standard, and there are lots of common mistakes in their drawings which can't reach the requirements of engineering application.

\section{B. Problems existed in performance evaluation system of drawing courses}

In traditional test mode, the examination paper are totally focused on the test of some single knowledge points, and it pay less attention to the engineering application and engineering practice.

Moreover, the part drawing and assembly drawing are most important contents in drawing courses, and they are also key test criterion to check and evaluate the learning outcomes and ability of engineering application. However, the test of these two contents is easy, and its complexity is not enough to reach the requirements of engineering application.

In addition, some common parts and standard parts are difficult to examine by closed-book test mode since it is not allowed to search for some parameter by the book.

\section{Requirements for the reform of drawing courses based on the OBE engineering education mode}

Outcomes-based Education mode originated from the reform of basic education in United States and Australia. Originally speaking, OBE model spread around the mail line as "define outcomes-realize outcomes-evaluate outcomes", and the evaluation of outcomes from the students' studying is the ultimate aim to realize the continuous improvement of teaching effect. Researcher Richard from United States presented a design model of courses based OBE mode, and the performance evaluation of students' studying was one of three important factor of this model ${ }^{[4,5]}$.

In the OBE mode, the education aim is prior to the teaching contents, and teachers can set up teaching unit by themselves without the rigid restriction of the teaching program. It is very important for teachers to predict and evaluate the outcomes of students' studying in this mode ${ }^{[6,7]}$.

Requirements of this mode for reform of drawing courses include four aspects as following:

- Pay more attention to cultivate the manual dexterity, team cooperation ability and innovation ability of students;
- Change the constant test method by one examination paper and evaluate studying performance and outcomes of students in different teaching unit by examining the expected ability in this course.

- Emphasize the cultivation of engineering application ability of students;

- Improve the student's abilities such as autonomic study ability, communication skills and verbal dexterity by the open type team project and discussing class without fixed model answer.

Students are expected to acquire three abilities as following by studying and practice training in drawing courses:

- Know well how to use the drawing instruments and tools to accomplish the drawing of standard engineering;

- Draw and read the engineering drawing of complex parts and equipment correctly;

- Express their designing idea and expressing method for complex engineering parts and equipment clearly and fluently, and communicate with industry peers effectively and expertly.

\section{REFORM PRACTICE OF DRAWING COURSES IN YANSHAN UNIVERSITY}

The OBE model has been applied and popularized to the reform of advanced engineering education system in Chinese colleges and universities for several years. In recent years, the CDIO and OBE mode have been expanded in the College of Mechanical Engineering of Yanshan University for the Education Reform, and the team project and discussing class project have been added in all the profession courses. Moreover, PowerPoint presentation for the project and discussing class has already been a regular part of profession courses. Drawing department of college of mechanical engineering has carried out the reform of drawing courses since 2012, and the blue print of reform has been determined in 2016 by several years' reform practice.

\section{A. The plans and measures of reform practice}

\section{1) Reform of teaching mode}

a) Set up the discussing class for the comprehensive expression of complex typical solid parts without a constant answer, and Encourage students to express it by different expression plans which accords with the national standards. Exercise the use of measuring devices and the flexible application of expressing methods, and cultivate the ability of finding and solving the questions by information retrieving and team discussing.

b) Set up group project for the measuring and drawing of assembly solid body, and deepen the students' comprehension on common assembly structure and standard parts and common parts by taking apart and assembling the equipment.

\section{2) Reform of Performance evaluation system}


a) Evaluation contents include 4 parts: homework (10 points), discussing class (10 points), team project(10 points) and examination paper(70 points),

b) In examination paper, the first question is comprehensive expression of the complex parts with a given axonometric projection, the full point this question is no less than 20 and not greater than 30 , and it is just needed to give the drawing without the size and technical specifications. The second question is reading the parts drawing, the full point of this question is about 20 , students are demanded to fill the blanks and draw a view or sectional view not given. The last question is parting the equipment and presenting the parts drawing, and the figures, sizes, tolerances, roughness and technical specifications. In addition, the knowledge of common parts and standard parts will be tested in the team project and discussing class.

\section{B. Detailed rules on reform of evaluation system}

- The group project and discussing class are all carried out in unit of a group with 6 members generally. Under the arrangement and organization of the leader of every group, the analyzing, measuring and drawing of the complex parts will be accomplished, and the drawings of parts and equipment based on the group project and discussing class should be submitted as an important basis to evaluate the performance of students in the end.

- Representatives from every group should give an oral presentation about 5 minutes to explain the idea of expressing the parts and equipment based on the drafts

- During the reporting progress, the other Representatives give a ranking of all groups except for the group reporter belongs to according to the performance and accomplishment of group project and discussing class, and all the groups will be sorted by the ratio $2: 4: 3: 1$ (For example, a class with 60 students can be divided into 10 groups, and the score of 2 groups within these 10 groups can get A . 4 groups can get B and 3 groups can get $\mathrm{C}$, and the group located on the bottom of group ranking lists have to be given a score $\mathrm{D}$.

- The template is designed so that author affiliations are not repeated each time for multiple authors of the same affiliation. Please keep your affiliations as succinct as possible (for example, do not differentiate among departments of the same organization). This template was designed for two affiliations.

\section{EVALUATION ON THE DEGREE OF ACHIEVING ABILITIES CULTIVATED BY THE DRAWING COURSES BASED ON THE OBE MODE}

Some achievements from the discussing class and team project were shown in Fig.1 and Fig.2. As shown in Fig.1 and Fig.2, students grasp the basic drawing skills and can accomplish the engineering drawing as expected.

For obtaining the degree of achieving the anticipated abilities from the teaching unit and drawing practice, the degree of achieving the 3 different abilities for every student were obtained by the ratio between the corresponding scores and the full marks, and it was shown in Table 1 .Furthermore, the mean degree of achieving abilities for every class can be obtained on the base of degree of achieving abilities for every student in this class, and it was shown in Table 2.

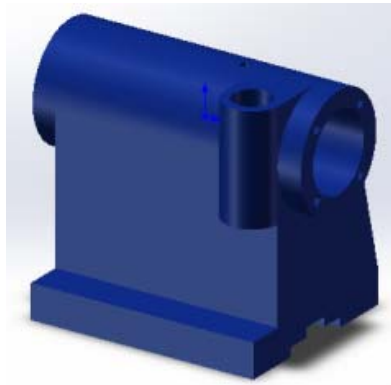

(a) Three-dimensional part drawing

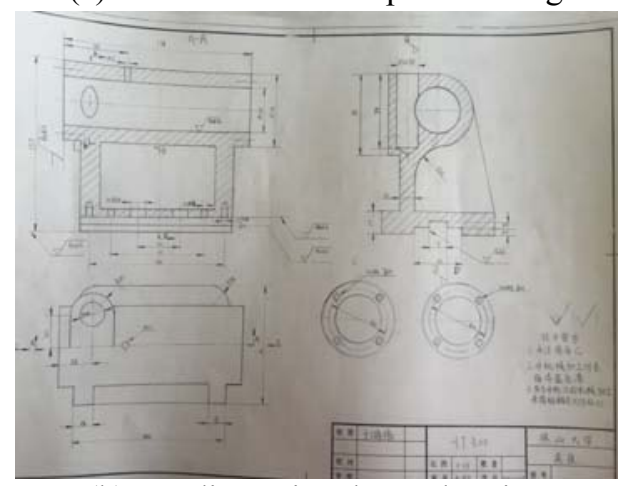

(b)two-dimensional part drawing

Fig. 1. Achievements show for the discussing class
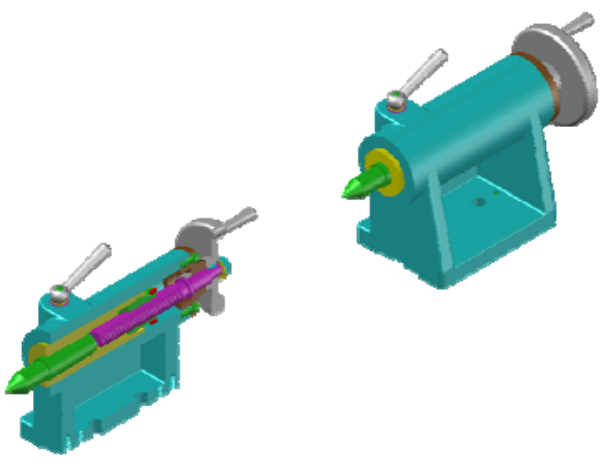

(a)Three-dimensional assembly drawing

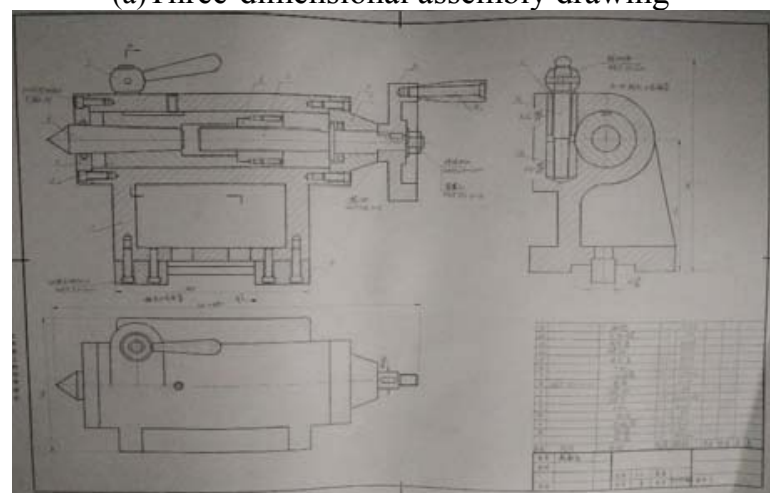

(b) Two-dimensional assembly drawing

Fig. 2. Achievements show for the team project 
TABLE I. ABILITY ACHIEVING DEGREE OF EVERY STUDENT

\begin{tabular}{|c|c|c|c|c|}
\hline \multirow{2}{*}{$\begin{array}{c}\text { Student } \\
\text { ID }\end{array}$} & \multicolumn{4}{|c|}{ Degree of Achieving Abilities } \\
\cline { 2 - 5 } & Ability 1 & Ability 1 & Ability 1 & Total \\
\hline $15 \ldots .001$ & 1.00 & 0.90 & 0.90 & 2.80 \\
\hline $15 \ldots .002$ & 0.90 & 0.91 & 0.90 & 2.71 \\
\hline $15 \ldots .003$ & 0.70 & 0.76 & 0.60 & 2.06 \\
\hline$\ldots \ldots \ldots$. & $\ldots \ldots$ & $\ldots \ldots$ & $\ldots$. & $\ldots \ldots$ \\
\hline
\end{tabular}

TABLE II. MEAN ABILITY ACHIEVING DEGREE OF ClASS

\begin{tabular}{|c|c|c|}
\hline Object & $\begin{array}{l}\text { Mean Degree of } \\
\text { Achieving } \\
\text { Abilities }\end{array}$ & Analyze of the cultivated object \\
\hline Ability 1 & 0.76 & $\begin{array}{l}\text { This cultivated object can be achieved } \\
\text { well, and students know how to } \\
\text { accomplish an engineering drawing by the } \\
\text { drawing instruments. But engineering } \\
\text { practice should be strengthened further. }\end{array}$ \\
\hline Ability 2 & 0.70 & $\begin{array}{c}\text { This cultivated object can be achieved } \\
\text { Basically, and students can grasp the basic } \\
\text { drawing skill. But comprehensive } \\
\text { engineering application ability is not } \\
\text { enough. }\end{array}$ \\
\hline Ability 3 & 0.73 & $\begin{array}{l}\text { This cultivated object can be achieved as } \\
\text { expected. Students can make a oral } \\
\text { presentation to express their idea and } \\
\text { communicate with industry peers. }\end{array}$ \\
\hline
\end{tabular}

\section{Measures to improve The Performance of teaching AND STUDYING CONTINUOUSLY}

For realizing the continuous improvement of teaching and studying, some measures should be taken to solve the problems found during the reform practice as follows:

- It takes considerable time and energy of students to carry out the team project, discussing class and report for getting a better performance. However the full marks of team project and discussing class are only 20 , it does not match the efforts and dedications to this class obviously. So, the score ratio of team project and discussing class should be added, and the full marks of team project and discussing class can be 40 ;

- A class with more than 60 students is not advantageous to the process of teaching and studying only if enough teaching assistants can be provided, and the number of students in a class should not greater than $30 \mathrm{~s}$ if possible;

- Drawing of some students can't reach the requirements of engineering application for the common mistakes and errors. So the students' training on drawing practice should be strengthened further.

\section{CONCLUSIONS}

Although some problems is always existed in the teaching reform of drawing courses, most of students can benefits from the reform practice of drawing courses based on the discussing class and team project. So, it is necessary to continue the reform exploration by improving the implementation plans and rules.

\section{REFERENCES}

[1] X. Li, L. Sun, Y. Wang and J. Gao. "A Research on the relationship between application levels of advanced manufacturing technology and market competitiveness of manufacturing company". Journal of Management Engineering,2004, Vol.4,pp.55-59(in Chinese)

[2] Z. Li, F. Lin. Development trend of engineering education with a view of engineering's essence, Research on the advanced engineering education, 2007, Vol.3, pp.17-21(in Chinese)

[3] Y. Xie. Reform on the development mode and management of Chinese engineering education courses, Research on the advanced engineering education, 2016 ,Vol.3, pp.34-38(in Chinese)

[4] X. Bai. Research on the cultivation mode of entrepreneurial engineering talents in Chinese colleges and universities.2011, Wuhan: Doctoral Dissertation of Huazhong University of Science and Technology(in Chinese)

[5] Y. Hai. Reform practice and analyze on the regional engineering colleges and Universities based on the OBE mode. Contemporary education theory and its practice,2015,Vol.4,pp.37-39(in Chinese)

[6] P. Gu, W. Hu. Engineering education mode based on "Outcomes-based education"-practice and exploration on the education reform in Shantou University, Research on the advanced engineering education, 2014, Vol.1, pp.27-37(in Chinese)

[7] X. Chen, G. Dai. Discussion about constructing the evaluation system of overall qualities for under graduate students in Chinese college and universities with a view of OBE engineering education mode. Zhe Jiang University of Technology(Social Science edition), 2015, Vol.4, pp.464467(in Chinese) 